\title{
Heterogeneity in CSR Spending Across Indian Companies: Results from Regression Clustering on a Large Panel-Data Model with Fixed Effects
}

\author{
Akhil Sankar, G.K. Gokul, Prashobhan Palakkeel
}

\begin{abstract}
CSR activities in India have a long history. However there have been numerous criticisms rose against the way in which the CSR activities are carried out by many of the Indian companies. Several studies found that more than half of the Indian firms failed to meet their mandatory requirements on CSR spending and report unspent funds in their financial statements. These issues show's that, there is a requirement to evaluate the behavior pattern of the firms' CSR spending activities. In this article, we try to describe the heterogeneity in the CSR related spending activities of the Indian companies. We follow the panel regression clustering approach developed by Sarafidis and Weber (2015). In this approach individual companies are grouped into a number of clusters and within each cluster, the slope parameters are assumed to be similar in nature. The difference in slopes across clusters is due to the standard error-components structure. As the clusters are heterogeneous, they do not share common parameters.
\end{abstract}

Keywords--- Panel Data Analysis, Heterogeneity, CSR, Regression Clustering, Fixed Effects.

\section{INTRODUCTION}

Corporate social responsibility (CSR) can be considered as one of the most important organizational policy and integral part of the business model for the modern enterprises. In many parts of the world, it is not right to consider it only as an internal code of conduct but has to be considered as a mandatory requirement for running the business.

CSR activities in India have a long history. However there have been numerous criticisms rose against the way in which these practices are carried out by many of the Indian companies. The dissatisfaction from these failures led to impose mandatory regulations on CSR spending by the Indian government during 2008 and 2012.

Studies explored various aspects of CSR activities and their impact on business. Many studies report that, CSR activities have a significant positive impact on many aspects of the business. Starting from financial benefits, studies show that, CSR activities can even contribute to the long term stability of the firms. Results from these studies are very important for the establishment of the CSR activities as natural and integral part of the business processes. The results from these studies can be used for motivating the reluctant firms.

Manuscript received September 16, 2019.

Akhil Sankar, MBA-MS Student, Department of Management, Amrita Vishwa Vidyapeetham, Bangalore. (e-mail: akhil6020@gmail.com)

G.K. Gokul, MBA-MS Student, Department of Management, Amrita Vishwa Vidyapeetham, Bangalore. (e-mail: gokulgk100993@gmail.com)

Prashobhan Palakkeel, Assistant Professor, Department of Management, Amrita Vishwa Vidyapeetham, Bangalore.

(e-mail: palakkeel@gmail.com)
Many studies found that more than half of the Indian firms failed to meet their mandatory requirements on CSR spending and report unspent funds in their financial statements. Present study tries to explore the heterogeneity in this behavior across Indian firms. The study mainly tries to find out whether size and nature of business (sector) play any significant role in creating this heterogeneity or not.

\section{REVIEW OF LITERATURE}

The literature about CSR is very rich and the literature explains various factors that would have significant impact on CSR. Studies explains that, access to finance to geographical dispersion have serious impact on CSR activities. Some of the studies report that, CSR activities increases shareholder value and help in enhancing the competitiveness [2].

The mutual dependence of financial strength and CSR spending are discussed in many studies. Some of them show that CSR performance depends on companies' access to finance [3]. On the other hand, some of the recent studies show that CSR expenditure has a positive impact on financial performance of the Indian banks [4]. Similarly, results show that firms with higher CSR scores have lower investment inefficiency [5]. There are evidences available in the literature which show that CSR impacts firm value also[6].

Some studies on American companies show that investors react positively when management spend and disclose for societal concerns [7]. Similarly other studies show that avoiding CSR concerns has significant consequences for firm performance and resources. Based on the social interaction argument some studies argue that corporate geographic dispersion can affect CSR [8].

While considering the CSR activities of Indian companies some of the studies assesses that, large private firms were highly reserved about mandatory contributions. One of them reported that more than half of Indian firms failed to meet their mandatory requirements on CSR spending [9].Some of the recent studies found that the outcome of the mandatory directions legislation has fallen short of expectations both in terms of the volume of expenditure and in number of activities [10].This discomfort showed by those firms indicates that they would not hold the greater commitment to CSR activities as expected for by the government. 


\section{HETEROGENEITY IN CSR SPENDING ACROSS INDIAN COMPANIES: RESULTS FROM REGRESSION CLUSTERING ON A LARGE PANEL-DATA MODEL WITH FIXED EFFECTS}

Although some of the studies were able establish a positive relationship between financial performance and CSR activities, most of the studies both in India and in other countries have been unable to establish a definitive answer as to the impact that CSR expenditure on company performance. This could be a reason for the reserved attitude of many of the companies in this regard.

Review of literature show that many aspects of CSR activities have been heavily researched. However, heterogeneity in the behavior of the firms related to the CSR activities is not much explored in the literature at least in the India. Most of the studies used descriptive techniques or indices in order to address the issues. Few studies used multiple regression models for explaining the relationship between the variables. However, these techniques are inadequate in explaining the heterogeneity in the CSR spending of the firms using the available big panel data.

Some of the recent studies tried to explore the unobserved heterogeneity with a new class of panel models [11][12]. One of the recent studies applied this model in Indian case [13]. These models are more suitable for panels with comparatively long time series component. However, present study uses a panel with short time series and large cross section components as per the availability of the data. So we consider another new class of models which is more suitable for our data. We follow the panel regression clustering approach developed by Sarafidis and Weber (2015).

\section{PREMISES OF THE RESEARCH}

\section{A. Formulation of Hypothesis}

In this paper, we try to analyze three main issues, i) Is size of the company really affect the CSR spending activities of Indian companies? ii) Is there exist heterogeneity in CSR spending across Indian companies? iii) Is the heterogeneity in CSR spending caused by sectoral differences?

Based upon these research questions we state three hypotheses

1) H0: Size doesn't have any serious role in deciding the pattern of CSR spending activities ofIndian companies.

2) H0: There is no heterogeneity exists across Indian companies in pattern of CSR spending activities.

3) H0:The heterogeniety in the pattern of CSR spending activities are not related with sectoral differences.

\section{DATA AND METHODOLOGY}

The data is collected from the Prowess database. Prowess provides information about the average net profit for last three financial years(ANP), CSR expenditure to be incurred as per Companies Act 2013(CSRE), Amount spent on CSR activities during the year (ASCSR) and CSR amount unspent(AUCSR). In the initial stage we considered all available information. It is a panel of 2817 companies over three years from 2014 to 2018 which consist of 8451 observations. Observations on 2014 and 2018 are removed from the sample because of very few entries.

The relationship between the actual CSR spending and the amount prescribed by the company act can be modeled as linear regression equation. The equation can estimated using OLS. For this purpose, we used a data set, in which variables are averaged for 3 years. By avoiding NA's, we get a sample data which consists of 1191 companies.

$$
y_{i}=\beta^{\prime} x_{i}+u_{i}
$$

For the panel data we can specify the regression clustering model with fixed effects as

$$
y_{i c t}=\beta_{c}^{\prime} x_{i c t}+u_{i c t}(2)
$$

In equation $2, y_{i c t}$ is the actual CSR spending of the $i^{\text {th }}$ company on $\mathrm{t}^{\text {th }}$ year. $\mathrm{x}_{\text {ict }}$ is the amount of money has to spend by the company according to the company act on the particular year. The subscript "c" denotes the cluster in which the company belongs to. The error component $u_{i c t}$ is composite in nature and follows a one-way error component model. Here ML estimation is used.

Sarafidis and Weber 2015) introduced a partitional clustering approach to get optimum number of clusters [1]. The approach is more effective in short panels in which time duration is relatively small and cross sectional part is large. In this regard, our data is completely suitable for the model. We use a balanced panel by removing the companies with unavailable information from the initial panel. The balanced panel data set has 3573 observations in total.

We use 'xtregcluster' procedure in Stata developed by Christodoulou D and Sarafidis V (2017) for estimating the regression clustering model [14]. Other Stata panel data commands like 'xtset' and 'xtreg' also used for data setting and estimation of the class of models. For data preparation, other computations and visualization, we use $\mathrm{R}$ computational environment.

\section{DATA EXPLORATION}

CSRE is defined as 2percent of ANP according to the Companies Act. CSRE ranges from -88 crores (Rupees) to 6606 crores with a median of 5.1crores. ASCSR ranges from 0 to 7606 crores with a median of 4 crores.ASCSR ranges from 0 to 2023 crores. All these variables are highly positively skewed (See Table.1).

Table 1: Summary Statistics

\begin{tabular}{|l|l|l|l|l|l|}
\hline & ANP & CSRE & ASCSR & AUCSR & Diff \\
\hline Min & -8498 & -87.9 & 0 & 0 & -2276 \\
\hline 1st Q & 100.8 & 2.1 & 1.5 & 1.3 & 0 \\
\hline Median & 247.5 & 5.1 & 4 & 3.3 & 0 \\
\hline Mean & 2065.6 & 42.4 & 41.3 & 19.4 & 8.4 \\
\hline 3rd Q & 683.3 & 14.1 & 12.1 & 8.4 & 2.9 \\
\hline Max & 330300 & 6606 & 7605 & 2023 & 1727 \\
\hline NA's & 1294 & 1346 & 2851 & 4705 & 2912 \\
\hline
\end{tabular}

\section{RESULTS AND DISCUSSION}

An evaluation of the relationship between CSRE and ASCSR from a balanced panel created from the initial data frame by averaging for each company shows that, 93 percent variation ASCSR is explained by CSRE (see table.2). 
The coefficient of CSRE shows that one percent increase in CSRE increases ASCSR by 0.93 percent. It clearly indicates that, companies just follow the rules in CSR spending than in voluntary terms

Table 2: Regression results from averaged for company's data

\begin{tabular}{|l|l|l|}
\hline Coefficients & Estimates & $\mathrm{p}$-values \\
\hline Intercept & -4.96 & 0.0527 \\
\hline CSRE & 0.93 & $2 \mathrm{e}-16$ \\
\hline $\mathrm{R}^{2}$ & 0.9313 & NA \\
\hline $\mathrm{F}$ & $1.612 \mathrm{e}+04$ & $2.2 \mathrm{e}-16$ \\
\hline
\end{tabular}

In order to specify the regression model for the panel data, we used the Hausman specification test. Hausman specification test rejects random effect model $\left(\chi^{2}=35.97, \mathrm{p}\right.$ value 0.000$)$, so we confirmed the fixed effect model. The fixed effect model without clustering specification show's that, overall 90 percent variation in the CSR expenditure can be explained by the model (See table.3).

Table 3: Fixed effect model regression results

\begin{tabular}{|l|l|l|}
\hline Statistic & Coefficient & p-value \\
\hline $\mathrm{R}^{2}$ Within & 0.31 & $\mathrm{NA}$ \\
\hline $\mathrm{R}^{2}$ Between & 0.93 & $\mathrm{NA}$ \\
\hline $\mathrm{R}^{2}$ Overall & 0.90 & $\mathrm{NA}$ \\
\hline $\mathrm{F}$ & 1052.99 & 0.000 \\
\hline Slope & 0.78 & 0.000 \\
\hline Intercept & 5.36 & 0.010 \\
\hline
\end{tabular}

In order to specify the cluster specification, we followed the standard procedure by starting with minimum number of clusters. We started with 2 to 3 clusters. The within group $\mathrm{R}^{2}$ for the first two clusters seems to be good. However, within group $\mathrm{R}^{2}$ for the third cluster is quite low (see table.4). The slope differences in the three clusters are shown in figure.1. It clearly shows the heterogeneity across the clusters.

Now we can discuss about some more descriptive statistics about the clusters. As mentioned before, the variables, CSRP and ASCSR are heavily skewed. So median could be a better measure of central tendency for the comparison. As per the median CSRE of the companies, there is no significant difference across the clusters ( $\mathrm{p}$-value 0.96). It also indicates that, in this classification, average size of the companies (based on net profit) is similar across clusters (see table.5). On the other hand, there is a significant difference exists in the CSR spending across clusters ( $\mathrm{p}$-value 0.001). This difference is visible at least across two groups (see table.5). Figure-3 show that proportion of green dots are much higher in group 2 which reflects the corresponding values in table-5. The p-values are generated following Mood's median test using $\mathrm{R}$ computational environment. Another observation from the clustering activity is that, all types of companies are included in the three clusters. So there is no heterogeneity exist across the clusters based on sectors.

Table 4: Regression cluster results for 3clusters

\begin{tabular}{|l|l|l|l|l|}
\hline Coef & $\Omega 1$ & $\Omega 2$ & $\Omega 3$ & Pooled \\
\hline$\beta$ & -0.886 & 1.157 & 0.147 & 0.782 \\
\hline$\alpha$ & 160.17 & -14.95 & 49.29 & 5.36 \\
\hline N_g & 187 & 744 & 260 & 1191 \\
\hline$\check{T}$ & 3 & 3 & 3 & 3 \\
\hline N & 561 & 2232 & 780 & 3573 \\
\hline $\mathrm{R}^{2} \_\mathrm{W}$ & 0.29 & 0.74 & 0.01 & 0.31 \\
\hline$\rho$ & 1.00 & 0.71 & 0.91 & 0.63 \\
\hline $\mathrm{r}$ & -0.99 & -0.86 & 0.93 & 0.51 \\
\hline
\end{tabular}

Table 5: Median across clusters

\begin{tabular}{|l|l|l|}
\hline Clusters & ASCSR & CSRE \\
\hline 1 & 4.3 & 7.0 \\
\hline 2 & 6.9 & 7.6 \\
\hline 3 & 3.7 & 7.7 \\
\hline
\end{tabular}

The classification experiment is extended for higher number of clusters in order to find an optimum number of clusters. However, within group $\mathrm{R}^{2}$ is not impressive for many clusters (see table 6). Moreover, in some of the clusters, very few companies are included. Due to this reason, we conclude the experiment with maximum of 3 clusters.

Table 6: Regression statistics for various clusters

\begin{tabular}{|l|l|l|l|}
\hline Cluster & $\beta$ & $\alpha$ & $\mathrm{R}^{2} \_\mathrm{W}$ \\
\hline$\Omega 1$ & 0.62 & -1.74 & 0.68 \\
\hline$\Omega 2$ & -1.02 & 178.6 & 0.32 \\
\hline$\Omega 2$ & 1.0 & -3.05 & 0.95 \\
\hline$\Omega 3$ & 1.14 & -11.22 & 0.94 \\
\hline$\Omega 4$ & 0.17 & 42.54 & 0.01 \\
\hline$\Omega 5$ & -2.23 & 109.16 & 0.08 \\
\hline$\Omega 6$ & 2.02 & -84.91 & 0.55 \\
\hline$\Omega 7$ & 0.78 & 2.357 & 0.31 \\
\hline
\end{tabular}

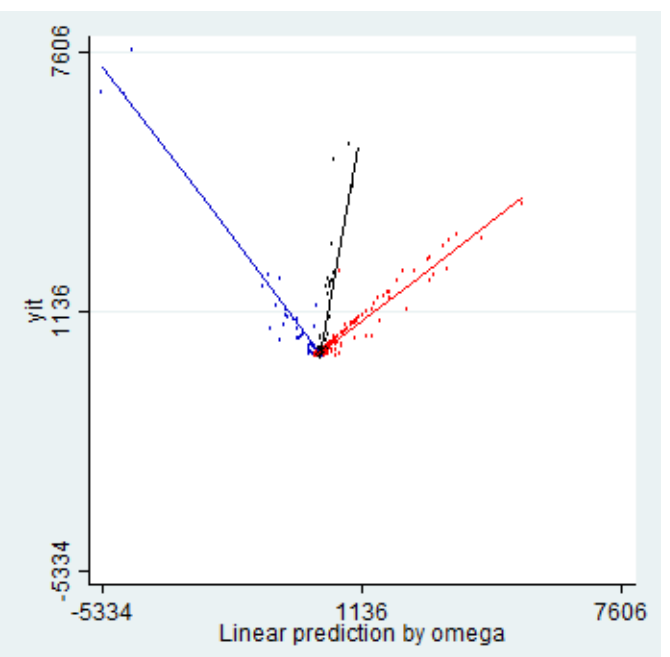

Figure 1: Heterogeneity in slope coefficients in 3 cluster model

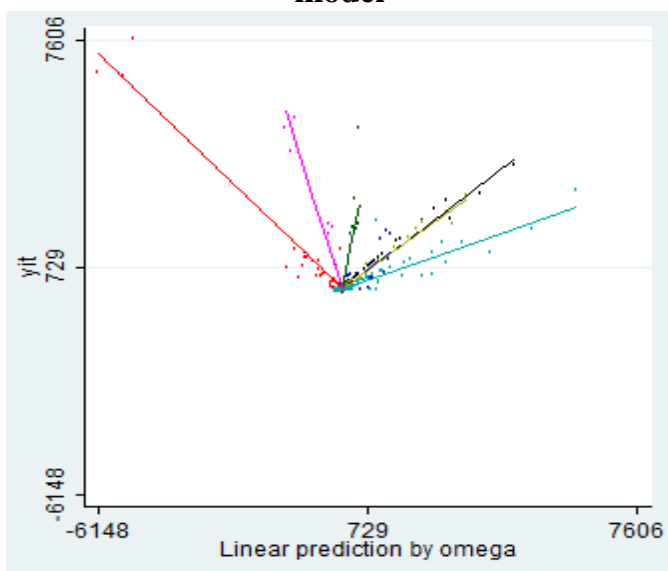

Figure 2: Heterogeneity in slope coefficients in 7 cluster model

Published By:

Blue Eyes Intelligence Engineering

\& Sciences Publication 


\section{HETEROGENEITY IN CSR SPENDING ACROSS INDIAN COMPANIES: RESULTS FROM REGRESSION CLUSTERING ON A LARGE PANEL-DATA MODEL WITH FIXED EFFECTS}

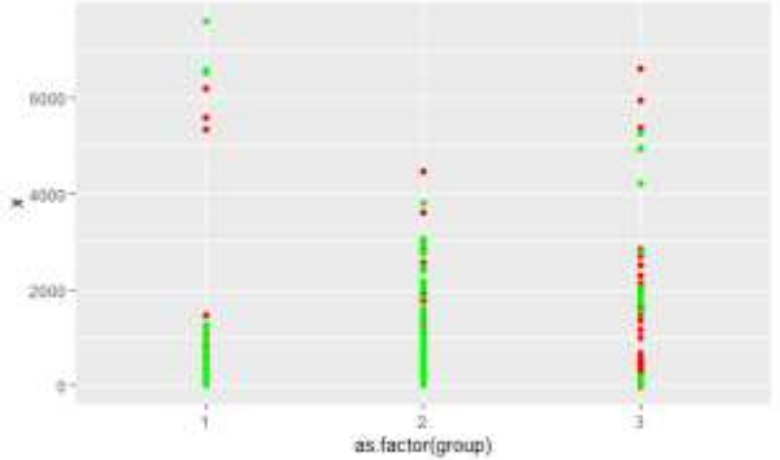

Figure 3: 3-Cluster membership pattern

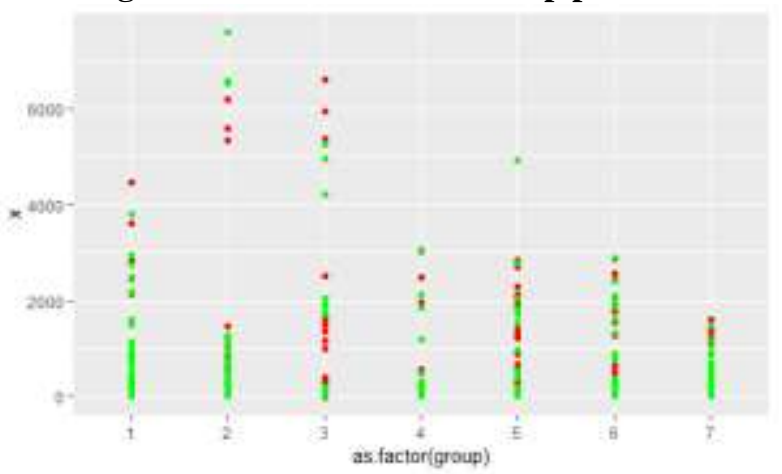

Figure 4: 7-Cluster membership pattern

\section{CONCLUSION}

This study tries to explore the heterogeneity in CSR spending behavior across Indian firms. The study mainly tries to find out whether size and nature of business (sector) play any significant role in creating this heterogeneity or not. Results from the regression clustering model on a large panel data with fixed effect clearly shows the heterogeneity existing among the firms in their CSR spending activities. However, there is no significant evidence to say that size of the firms or their nature of business contributes to this heterogeneity. The firm specific characteristics which are contributing to the heterogeneity have to be addressed in future research.

\section{REFERENCES}

1. Sarafidis.V and Weber. N, "A partially heterogeneous framework for analyzing panel data", Oxford Bulletin of Economics and Statistics, 77, 274-296, 2015

2. Kim M and Kim, Y, "Corporate social responsibility and shareholder value of restaurant firms", International Journal of Hospitality Management, 40, 120-129, 2014

3. Cheng. B, Ioannou. I, Serafeim. G, "Corporate social responsibility and access to finance", Strategic Management Journal, 35, 1-23, 2014

4. Maqbooln.S and Zameern. M. N, "Corporate social responsibility and financial performance: An empirical analysis of Indian banks", Future Business Journal,4, 8493, 2018

5. Benlemlih.M,Bitar, M, "Corporate social responsibility and investment efficiency", Journal of Business Ethics, $143,1-25,2016$

6. Servaes. H and Tamayo. A,"The impact of corporate social responsibility on firm value: the role of customer awareness", Journal of Management Science, 59, 10451061,2013

7. Martin. P.R and Moser. D.V.( 2016) Managers' green investment disclosures and investors' reaction. Journal of Accounting and Economics, 61, 239-254.
8. Shi G, Jianfei Sun J, Zhang L and Jin Y, "Corporate social responsibility and geographic dispersion", Journal of Accounting and Public Policy, 36, 417-428, 2017

9. Singh. S, "Corporate social responsibility spend in FY2016: Majority fails to do the minimum The Indian Express". Retrieved from https://indianexpress.com/article/india/india-newsindia/fy15-corporate-social-responsibility-spendmajority-fails-to-do-the-minimum-2962695, 2016

10. Mukherjee A, Birdb R and Duppati G, "Mandatory Corporate Social Responsibility: The Indian experience", Journal of Contemporary Accounting \& Economics, 14, 254-265, 2018

11. Kneip A, Sickles RC, Song W, "A New Panel Data Treatment for Heterogeneity in Time Trends", Econometric Theory, vol.28, no.3, pp.590-628, 2012

12. Bai J, "Panel Data Models with Interactive Fixed Effects", Econometrica, vol.77,no.4, pp.1229-1279, 2009

13. Mavila SN, Pillai A and Palakkeel P, "Sectoral Disproportionateness under Heterogeneous Time Trends: A Study across Indian States", International Conference on Recent Trends in Computational Engineering and Technologies (ICTRCET'18), May 17-18, Bangalore, India, 2018

14. Christodoulou D and Sarafidis V, "Regression clustering for panel-data models with fixed effects", The Stata Journal, 17, Number 2, pp. 314-329, 2017 